\title{
The assessment of exhaust system energy losses based on the measurements performed under actual traffic conditions
}

\author{
P. Fuc ${ }^{1}$, J. Merkisz ${ }^{1}$, P. Lijewski ${ }^{1}$, A. Merkisz-Guranowska ${ }^{2}$ \\ \& A. Ziolkowski ${ }^{1}$ \\ ${ }^{1}$ Institute of Combustion Engines and Transport, \\ Poznan University of Technology, Poland \\ ${ }^{2}$ Institute of Machines and Motor Vehicles, \\ Poznan University of Technology, Poland
}

\begin{abstract}
It is generally acknowledged that energy losses from the exhaust system are approximately $30 \%$ of the total losses of energy supplied to the engine in the form of fuel. Part of this energy is used to heat the aftertreatment systems whose pollutant conversion rate is tightly related to their operating temperature. The exhaust gas flowing through the catalytic supports of the converters and filters warms them up while the outstanding energy contained in the gases is lost permanently. Hence, it is vital to recuperate the waste energy and convert it into different forms such as electrical energy using thermoelectric modules. In this paper, we determined the energy loss in an exhaust system of a city bus following the measurements carried out under actual traffic conditions on a regular bus route. The measurements of the exhaust gas temperature and mass flow were performed at three points. For this, thermoresistors and a portable exhaust emission analyzer SEMTECH DS (designed for exhaust emission testing under actual traffic conditions) were used. Based on the measured exhaust emission of $\mathrm{CO}_{2}, \mathrm{CO}$ and $\mathrm{THC}$ we determined the vehicle gas mileage. From the vehicle diagnostic system, we pulled basic data of the engine operation and based on this, the amount of energy supplied to the engine and the losses through the exhaust system throughout the entire test run of the bus were determined.

Keywords: energy losses, actual traffic conditions.
\end{abstract}




\section{Introduction}

The efficiency of piston combustion engines reaches 30-40\% except low speed two stroke marine engines, whose efficiency may reach up to $50 \%$. Analyzing the energy balance in engines of automotive applications it is observed that only $30-40 \%$ of the chemical energy supplied with the fuel is converted into mechanical work. The outstanding energy is lost due to: a) thermal losses through the cooling system, b) thermal losses through the exhaust system, c) the losses of incomplete or partial combustion and d) other thermal losses.

For decades intense scientific research has been conducted aiming at a reduction of thermal losses, thus an improvement of the overall efficiency of piston combustion engines. One of the trends is the development of methods of recovery of waste energy from the exhaust gases. Thus far, the basic method of recovery was the application of turbochargers, particularly in diesel engines. The principle of operation of a turbocharger is based on using the energy of the exhaust gas flow to drive the turbine connected with the compressor through a shaft. The compressor increases the pressure of fresh medium fed to the combustion chamber. The density of the medium is changed and we can deliver more fuel to the cylinder, which results in a greater engine power. Turbocharger systems are undergoing constant modifications, which results from a dynamic advancement of the design of piston combustion engines in terms of reduction of the exhaust emissions and fuel consumption. Emission reduction in modern engines determines their advancement. The fundamental tools used by the legislators in this respect are exhaust emissions standards that prescribe the exhaust emission limits and the procedures of their measurements. Until recently, the limits of the emission of $\mathrm{CO}_{2}$ were not applicable (it is tantamount to the fuel consumption), yet the European Commission introduced $\mathrm{CO}_{2}$ emission limits measured from the entire fleet of a single manufacturer starting from 2015. This limit will amount to $140 \mathrm{~g} / \mathrm{km}$ [1-4].

Beside works on the improvement of the engine supercharging systems, investigations are underway related to other forms of exhaust gas energy recovery. In Dingel et al. [5], alternative methods of conversion of this type of energy have been presented and analyzed, i.e. the conversion of thermal energy into electrical energy using the TEG technology (Thermoelectric Generator) and AMTEC (Alkali Metal Thermal to Electric Converter). The selection of an optimum method of conversion, however, requires determining of the energy balance with a particular focus on the losses from the exhaust system. The paper presents a method of determination of a simplified energy balance of an engine under actual conditions of operation and the obtained results of the thermal losses (performed on a city bus).

\section{Energy balance of a combustion engine determined under actual conditions of operation}

The energy balance of a combustion engine is mainly calculated under laboratory conditions on engine test beds. In this method a series of parameters is measured based on which individual energy losses are calculated. These include the 
measurement of: fuel consumption, intake air temperature, exhaust gas temperature and mass flow, inlet and outlet coolant temperature, the coolant flow, engine speed, engine load etc. A detailed description of this method can be found in $[6,7]$. Yet, on traditional engine test beds it is impossible to reproduce dynamic states of engine operation that simulate actual vehicle driving cycles including not only the speed profile but also the vehicle parameters and driver behavior. To this end, the authors have developed a method of determining of the energy balance of a combustion engine based on the measurements performed under vehicle actual operating conditions. This paper will present a simplified version of this method serving a purpose of determining the amount of energy supplied to the engine with the fuel and the exhaust gas energy losses.

The energy supplied to the engine with the fuel $Q_{F U E L}$ is calculated as follows:

$$
Q_{F U E L}=G_{s} W_{u}
$$

where:

$Q_{F U E L} \quad$ - energy supplied with the fuel [kW],

$G_{s} \quad-$ second-by-second fuel consumption $[\mathrm{g} / \mathrm{s}]$,

$W_{u} \quad-$ fuel calorific value $[\mathrm{kJ} / \mathrm{kg}]$.

The second-by-second fuel consumption can be calculated from the fuel consumption value pulled from the OBD system. Usually, the fuel consumption is expressed in $\mathrm{dm}^{3} / \mathrm{s}$ and in this case, the obtained values need to be multiplied by the fuel density. If the OBD system of a vehicle does not record the fuel consumption values, the carbon balance method must be employed in the following form:

$$
G_{s}=a\left[(0.866 \mathrm{THC})+(0.429 \mathrm{CO})+\left(0.273 \mathrm{CO}_{2}\right)\right]
$$

where:

$G_{s} \quad-$ second-by-second fuel consumption $[\mathrm{g} / \mathrm{s}]$;

$a \quad-$ for spark ignition engines $\mathrm{a}=1.154$; foe diesel engines $\mathrm{a}=1.155$;

$\mathrm{THC}, \mathrm{CO}, \mathrm{CO}_{2}-$ emission mass flow $[\mathrm{g} / \mathrm{s}]$.

Exhaust gas energy losses $Q_{\text {EXHAUST }}$ are determined according to formula:

$$
Q_{E X H A U S T}=m_{E X} c_{p E X} T_{E X}
$$

where:

$Q_{\text {EXHAUST }}-$ exhaust gas energy losses [kW],

$m_{E X} \quad-$ exhaust gas mass flow $[\mathrm{kg} / \mathrm{s}]$,

$c_{\text {pex }}-$ exhaust gas specific heat at a constant pressure $[\mathrm{kJ} /(\mathrm{kg} \cdot \mathrm{K})]$,

$T_{E X} \quad$ - exhaust gas temperature [K].

\section{Methodology}

\subsection{Route test}

In order to most accurately reflect the operating conditions the authors decided to carry out the tests on an actual bus route in Poznan (operated by MPK Poznan local bus operator). Bus route 76, as the most heavily loaded one in Poznan, was 
selected for the tests (Fig. 1). Its length amounts to approximately $16 \mathrm{~km}$ and it has 43 bus stops. It starts in the northern part of the city, goes through the downtown area and ends in the southern part of the city near the A2 expressway. A large number of bus stops and the trajectory of the route are responsible for the high oscillation of the accelerations, which significantly influences the exhaust emissions and fuel consumption.

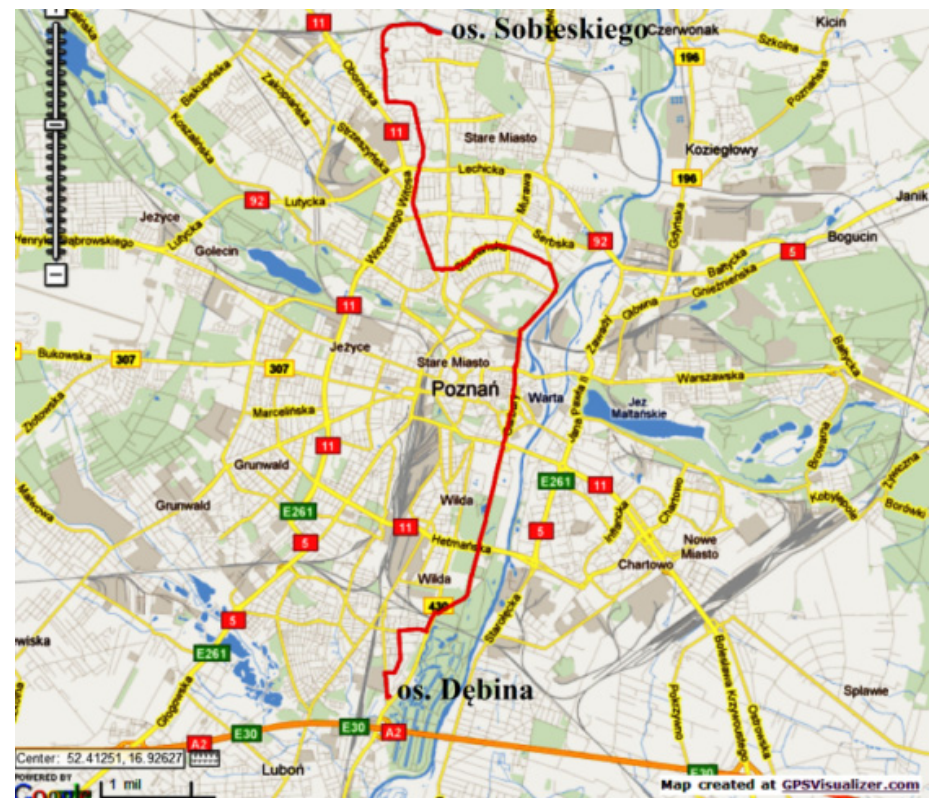

Figure 1: The route used for the vehicle test (created at GPSVisualizer.com].

\subsection{Research object}

For the tests a diesel city bus with a length of 18 meters was used. The vehicle was fitted with an engine of the displacement of $9.2 \mathrm{dm}^{3}$ and the power output of $231 \mathrm{~kW}$ (Table 1), a selective catalytic reduction system and a diesel particulate filter.

Table 1: Characteristics of the tested bus.

\begin{tabular}{|c|c|}
\hline Parameter & Value \\
\hline Ignition & Compression ignition \\
\hline Displacement & $9.2 \mathrm{dm}^{3}$ \\
\hline Number of cylinders & 6 \\
\hline Maximum power output & $231 \mathrm{~kW} \mathrm{@} 1900 \mathrm{rpm}$ \\
\hline Maximum torque & $1275 \mathrm{Nm}$ at \\
& $1100 \div 1710 \mathrm{rpm}$ \\
\hline Emission standard & EEV \\
\hline After treatment & DPF $/ \mathrm{SCR}$ \\
\hline
\end{tabular}




\subsection{Measurement system}

For the measurement of the concentrations of the exhaust emission components the authors used a portable exhaust emissions analyzer SEMTECH DS by SENSORS (Fig. 2). The analyzer measures the concentration of the exhaust components and simultaneously measures the flow rate of the exhaust gases. The exhaust gases are introduced into the analyzer through a probe maintaining the temperature of $191^{\circ} \mathrm{C}$. Then, the particulate matter is filtered out (diesel engines) and the exhaust gas is directed to the flame-ionizing detector (FID) where the concentration of THC (total hydrocarbons) is measured. The exhaust gas is then chilled to the temperature of $4^{\circ} \mathrm{C}$ and the measurement of the concentration of $\mathrm{NO}_{\mathrm{x}}$ (nitric oxides, NDUV analyzer), $\mathrm{CO}, \mathrm{CO}_{2}$ (carbon monoxide, carbon dioxide, NDIR analyzer) and $\mathrm{O}_{2}$ follows in the listed order. It is possible to add data sent directly from the vehicle diagnostic system to the central unit of the analyzer and use the GPS signal (Global Positioning System) [8, 9].

The measurements of the temperature in the exhaust system of a bus were performed using three thermoresistors fitted in the following configuration (Fig. 3):

a) Thermoresistor $t_{1}$ - fitted at the mid-length of the SCR catalytic converter.

b) Thermoresistor $t_{2}$ - fitted $0.4 \mathrm{~m}$ from the outlet of the SCR converter.

c) Thermoresistor $t_{3}$ - fitted $0.6 \mathrm{~m}$ from the outlet of the SCR converter.

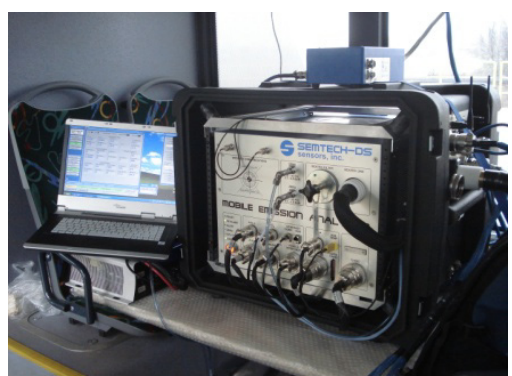

(a)

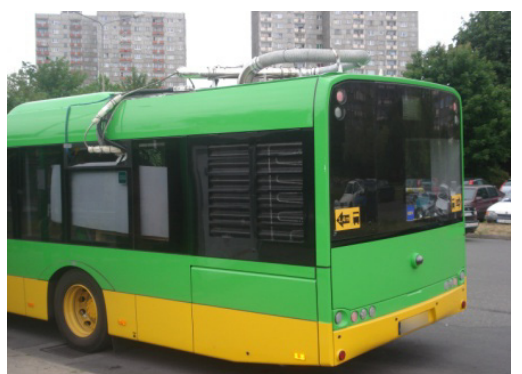

(b)

Figure 2: View of the portable exhaust emission analyzers SEMTECH DS (a) and the exhaust flow meter (b).

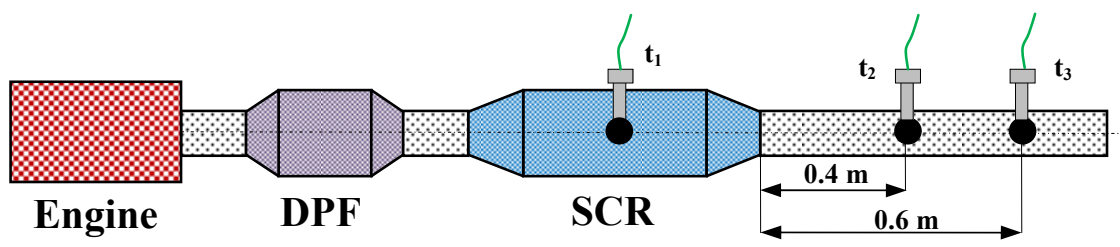

Figure 3: Location of the thermoresistors in the exhaust system of the tested bus. 


\section{Results of measurements}

\subsection{Analysis of the recorded actual driving cycle of the bus}

From the recorded actual driving cycle of the tested bus described with the function relation $\mathrm{f}=\mathrm{V}(t)$ and $\mathrm{f}=\mathrm{a}(t)$ it results that the vehicle test run was characterized by a very high variability of speed, and consequently acceleration, as shown in Fig 4(a). The average vehicle speed on the entire route was 22.63 $\mathrm{km} / \mathrm{h}$ and the maximum $-55 \mathrm{~km} / \mathrm{h}$. At this point, we need to note that the measurements were conducted on Saturday around noon when the vehicle traffic is much lower than on a regular workday. This leads to a conclusion that the bus average speed is higher than regular. It is also noteworthy that the share of vehicle stops was only $21 \%$ of the total test time, as shown in Fig. 4(b) that lasted for 2735 seconds. A vehicle drive with a constant speed has not been recorded.

Such driving conditions have direct influence on the bus engine characteristics - high variability of speed and accelerations determines the variability of the engine speed and load, hence mass flow of the exhaust gas and its temperature. The last two parameters are also impactful on the operation of the DPF and SCR influencing their light-off and course of the catalytic processes (chiefly endothermic). Depending on the basis of the above it is possible to determine the waste energy losses of the exhaust gas in a wide range of operation of the engine and the catalytic systems.

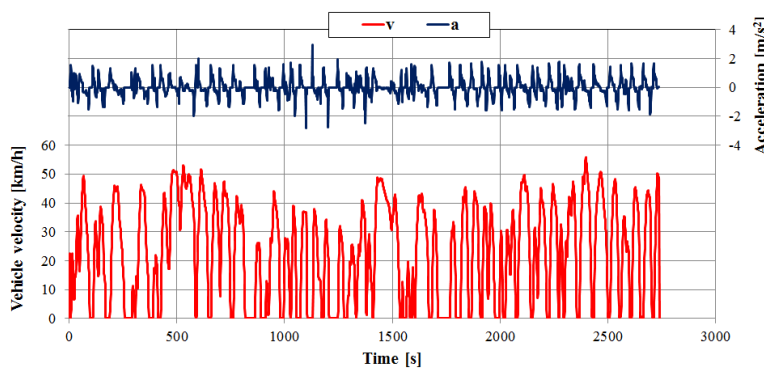

(a)

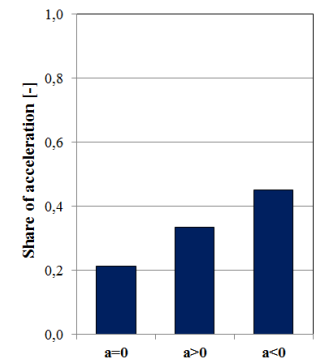

(b)

Figure 4: The tracings of the speeds and accelerations in the actual driving cycle of the tested bus (a) the share of phases and accelerations (b).

\subsection{Analysis of the temperature and exhaust gas mass flow rate}

The highest exhaust gas temperature was recorded in the SCR catalytic converter (Fig. 5). It amounted to a maximum of $336^{\circ} \mathrm{C}$. The authors also observed that the temperature varied in the range $230-300^{\circ} \mathrm{C}$. At points $t_{2}$ and $t_{3}$ the value of the temperatures was much lower than at point 1 and it did not exceed $195^{\circ} \mathrm{C}$. The temperature difference between points 1 and 2 varied in the 
range $34-144^{\circ} \mathrm{C}$ (Fig. 6). Much smaller differences occurred between points 2 and 3 amounting to a maximum of $13^{\circ} \mathrm{C}$. Such a great divergence of the temperature difference for the first case is attributed to the energy transfer to the SCR catalytic support and to the endothermic nature of the reaction of reduction occurring there. Because of those reactions, the temperature of the exhaust gas flowing out of the catalytic converter is reduced. The temperature drop is also influenced by the large heat exchange area in on the exhaust gas the exhaust system walls - ambient air. The influence of the heat exchange on the temperature drop is not as significant as the influence of the SCR catalytic converter, because on the length of 0.2 meter (between points 2 and 3) a

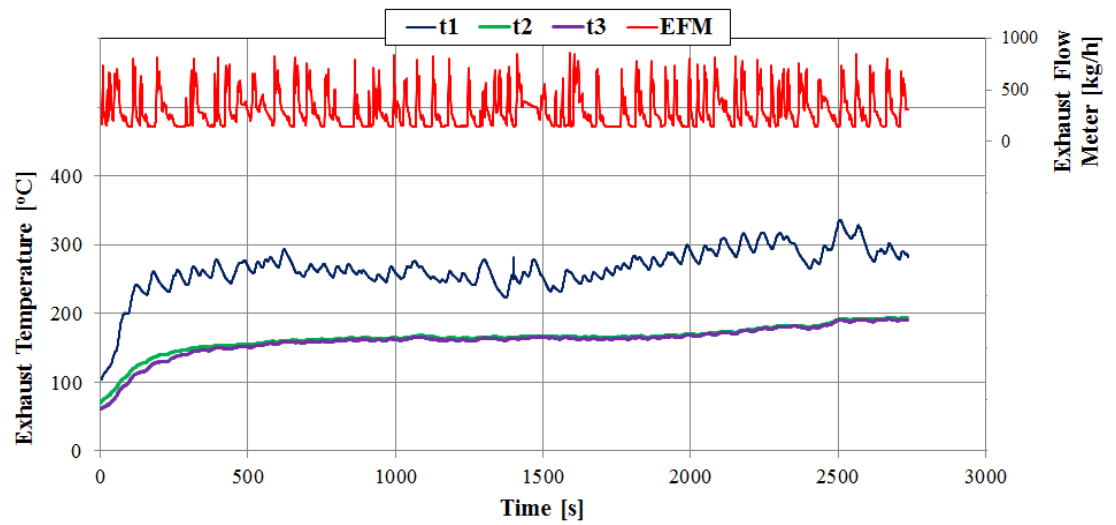

Figure 5: Tracings of the exhaust gas temperature and the mass flow of the exhaust gas recorded during the road tests.

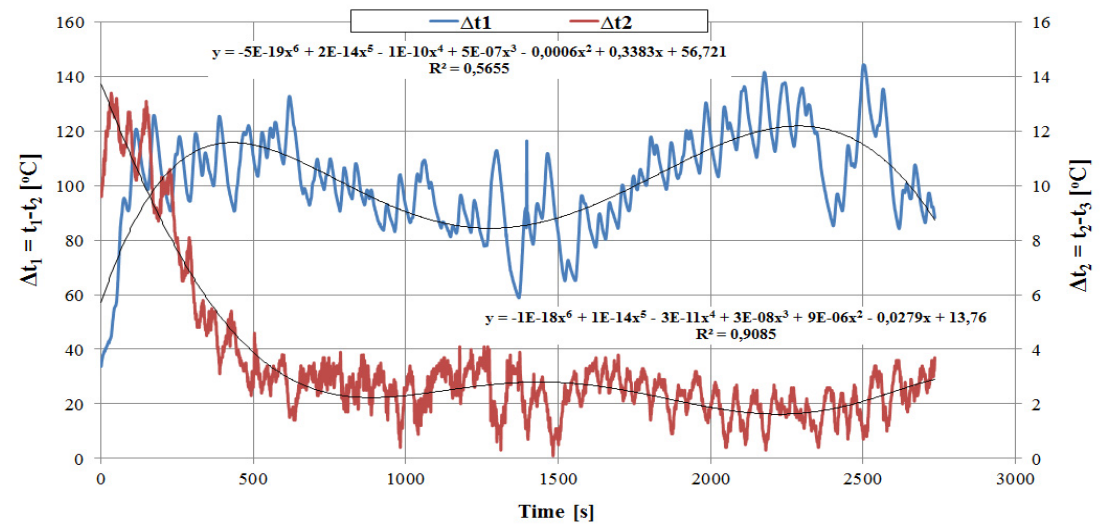

Figure 6: Tracings of the temperature differences between the measurement points together with the approximation functions. 
relatively low temperature drop was recorded. Both courses of the temperature differences between the measurement points were approximated by polynomial functions of degree 6 . For the first case the coefficient of determination was $\mathrm{R}^{2}=0.57$ and for the second $\mathrm{R}^{2}=0.91$. The mass flow of the exhaust gas during the road tests varied in the range of 140 to $860 \mathrm{~kg} / \mathrm{h}$ (Fig. 5).

\subsection{Energy balance}

Based on the recorded exhaust gas mass flow and its temperature in equation (3) the courses of the energy losses were determined at three measurement points (Fig. 7). In this case, the energy losses were chiefly influenced by the temperature of the exhaust gas and that is why the greatest losses were recorded for the first measurement point. They were $79.2 \mathrm{~kW}$. At the outstanding measurement points the maximum losses were $\mathrm{Q}_{2}=62.3 \mathrm{~kW}$ and $\mathrm{Q}_{3}=61.9 \mathrm{~kW}$ respectively.

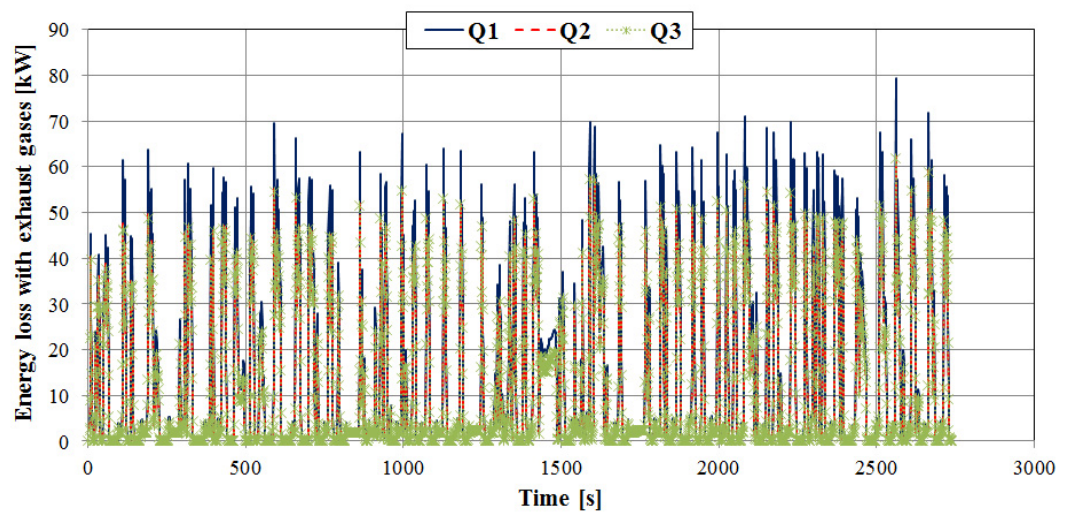

Figure 7: $\quad$ Exhaust gas energy losses at three measurement points.

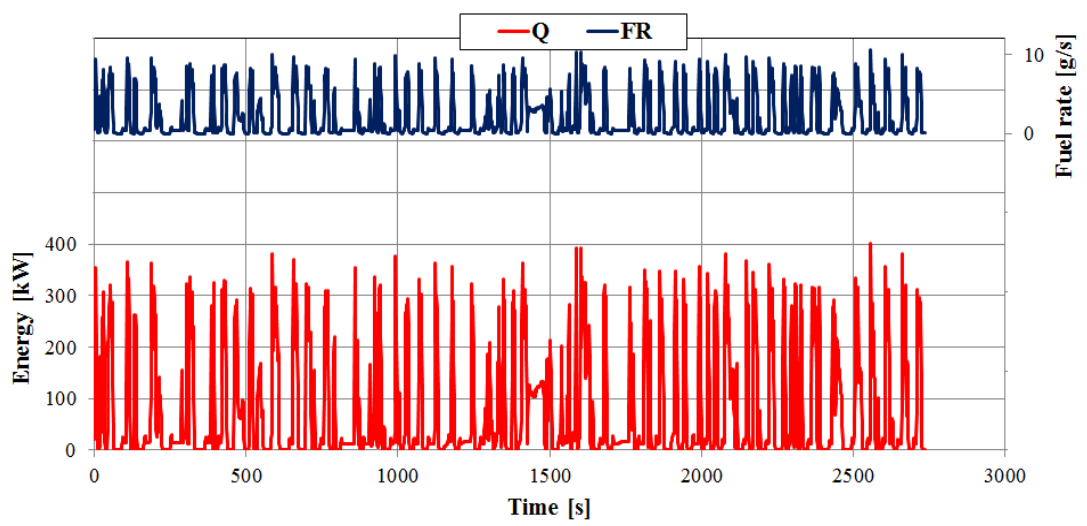

Figure 8: Tracings of the energy supplied to the engine and second-bysecond fuel consumption. 
Then, the energy supplied to the engine was calculated from formula (1). To this end second-by-second fuel consumption was determined based on the carbon balance method (2). For this, the measured THC, $\mathrm{CO}$ and $\mathrm{CO}_{2}$ emission flows were used obtained via SEMTECH DS (a portable analyzer). In the performed test the bus consumed $6.5 \mathrm{dm}^{3}$ of fuel, i.e. upon conversion into liters per $100 \mathrm{~km}$ this fuel consumption was $37.8 \mathrm{dm}^{3}$.

The share of the sum of energy losses from the exhaust gas in the total energy supplied with the fuel was as follows:

a) point $1-18.0 \%$;

b) point $2-14.6 \%$;

c) point $3-14.4 \%$.

\section{Conclusions}

In the paper, an empirical method of determining of the energy losses in the exhaust system of a city bus was presented following a series of tests under actual operating conditions. This method allows not only a qualitative determination of the energy losses but also a distribution of these losses in the individual sections of the exhaust system of a vehicle. When analyzing the obtained energy distribution in the vehicle exhaust system the authors observed that the majority of the exhaust gas energy is lost in the catalytic converters and particle filters (DPF). This is caused by the energy transfer to the supports of these converters and the utilization of energy for the catalytic chemical reactions. Such analyses constitute a basis for the development of a thermal energy recovery method from the exhaust gas by their recuperation. The key problem is appropriate location of the heat exchanger in the exhaust system to obtain the optimum thermal energy transfer.

\section{Acknowledgement}

The research was financed by Narodowe Centrum Nauki (National Science Centre) - research project (contract No. UMO-2011/01/B/ST8/07241).

\section{References}

[1] Thom R.W.: $\mathrm{CO}_{2}$-Avoidance - Targets, Measures, Costs What Contribution can E-Mobility provide? Thermoelectrics Goes Automotive II (Thermoelectrics III), pp. 10-29, 2013.

[2] Walsh M.P.: Global trends in motor vehicle pollution control; a 2011 update. Part 1. Combustion Engines / Silniki Spalinowe nr 2/2011 (145), pp. 106-117, 2011.

[3] Regulation (EC) no 443/2009 for the European Parliament and of the Council of 23 April 2009 setting emission performance standards for new passenger cars as part of the Community's integrated approach to reduce $\mathrm{CO}_{2}$ emission from light-duty vehicles. OJ L 140/1. 
[4] Regulation (EC) no 510/2011 for the European Parliament and of the Council of 11 May 2011 setting emission performance standards for new light commercial vehicles as part of the Community's integrated approach to reduce $\mathrm{CO}_{2}$ emission from light-duty vehicles. OJ L 145/1.

[5] Dingel O, Semper T, Ambrosius V., Seebode J.: Waste Heat Recovery: What are the Alternatives to the thermoelectric Generator? Thermoelectrics Goes Automotive II (Thermoelectrics III), pp. 30-49, 2013.

[6] Penhalbel, L., Ferreira, E., Dantas de Araújo, J., Sobral, M. et al., Methodology of Thermal Balance Test for Diesel engines, SAE Technical Paper 2008-36-0205, 2008.

[7] Singh, S., Garg, A., Gupta, A., Permude, A., Analysis of Thermal Balance of Diesel Engine and Identification of Scope for Waste Heat Recovery, SAE Technical Paper 2013-01-2744, 2013.

[8] Merkisz, J., Fuc, P., The Exhaust Emission from Light Duty Vehicles in Road Test in Urban Traffic, SAE Int. J. Fuels Lubr. 3(2):467-475, 2010.

[9] Merkisz J., Fuc P., Lijewski P., Ziolkowski A.: The on-road exhaust emissions from vehicles fitted with the start-stop system. Applied Mechanics and Materials Vol. 390 (2013), pp. 343-349. 